\title{
Retraction Note to: An analytical model for the effects of the variation of ferroelectric material parameters on the minimum subthreshold swing of NC-FETs
}

\author{
Raheela Rasool $^{1}$ - Najeeb-ud-Din ${ }^{1}$ - G. M. Rather ${ }^{1}$ \\ Published online: 31 December 2020 \\ ๑) Springer Science+Business Media, LLC, part of Springer Nature 2020
}

\section{Retraction Note to: \\ Journal of Computational Electronics \\ (2019) 18:1207-1213 \\ https://doi.org/10.1007/s10825-019-01395-3}

The Editors-in-Chief have retracted this article [1] as it has been previously published [2].

The authors of this article have not responded to any correspondence from the editor/publisher about this retraction.

[1] Rasool, R., Najeeb-ud-Din, Rather, G.M.: An analytical model for the effects of the variation of ferroelectric material parameters on the minimum subthreshold swing of NC-FETs. J. Comput. Electron. 18, 1207-1213 (2019). https ://doi.org/10.1007/s10825-019-01395-3
The original article can be found online at https://doi.org/10.1007/ s10825-019-01395-3.

Raheela Rasool

raheela_03phd14@nitsri.net

1 Department of Electronics and Communication,

National Institute of Technology, Srinagar,

Jammu \& Kashmir 190006, India
[2] Rasool, R., Rather, G.M.: Analytical model for the effects of the variation of ferrolectric material parameters on the minimum subthreshold swing in negative capacitance capacitor. J. Semicond., 40(12), 122401 (2019). https://iopsc ience.iop.org/article/10.1088/1674-4926/40/12/122401/meta

Publisher's Note Springer Nature remains neutral with regard to jurisdictional claims in published maps and institutional affiliations. 